\title{
The Application and Development of the Network Course Teaching
}

\author{
Sheng $\mathrm{Wu}^{1}$, Lirong $\mathrm{Ma}^{1,}$ a, $\mathrm{Na} \mathrm{Ni}^{2}$ \\ ${ }^{1}$ Information Management Centre of Flight Fundamental Training Base ,Aviation University of \\ Air Force, Chang Chun, 130022,China
}

${ }^{2}$ Aircraft Dynamics Department, Aviation University of Air Force, Chang Chun, 130022, China

aemail: malirong2000@163.com

\begin{abstract}
Keywords: Education Informationization; Network Course Teaching; Teaching Mode
\end{abstract}
\begin{abstract}
This paper discusses the concept of network course teaching, and the important status of network course in the modern teaching during the process of course reform and education informationization. It expatiate the necessary condition from the theory and practice, It also bring forward some of the measures combined schools teaching practice to promote network course teaching applications.
\end{abstract}

\section{The Meaning of the Network Teaching}

With the advent of the information age, the modern information technology is changing people's way of communication, ways of thinking, ways of working, lifestyle and people's learning styles with stupendous rate. Network teaching for us is no longer a strange word, it is continued to deepen in the field of education, it shows its great vitality and unlimited potential, the traditional teaching model has been a great challenge.

Network teaching have not a unified, standardized, but you can interpret it this way :those which rely on computer networks teaching activities is called the network teaching . It can have a variety of ways, such as online real-time interactive teaching, online real-time broadcasting, broadcast teaching and teaching through the network courseware, etc. There are two elements: First, the computer network ; the other is teaching activities, apparently teaching activities is the first element .These two elements is both important, must be present at the same time, otherwise it can't be called network teaching. So that you can easily distinguish the online education, online learning, distance learning, network teaching, network assistant teaching, computer assistant teaching, network school from each other. we defined as follows convenient for discuss: the network teaching activities carried out through the use of network teaching platform, during the activity , the students can complete the learning process of the whole course through the network, is called the network teaching .

The guiding ideology of the network course construction and application is that with the scientific development concept as a guide, based on the trends and characteristics of the development of educational theory and teaching practice , consider on the successful experience of domestic and foreign , military and non-military , make the students quality education and training as the main work, reform and implement the reform of the teaching mode, establish talent training mode combine with initiate knowledge, cultivate capacity and improve quality, rebuild the students quality connotation and talent standards, establish the human quality concept of comprehensive development, on the basis of professional education, pay more attention to the ability of acquire knowledge on students 's own initiative, a positive attitude, realistic and innovative spirit, strong sense of professionalism and sense of social responsibility culture .

\section{Propose the Problem}

In our country, network teaching has a certain foundation whether it is in the college or the secondary school. However, the practical application effect is unsatisfactory. It is not only the people's awareness and conceptual reasons, but also the consequences of defects on the 
management which is used in the new things. Today, many of our schools have in fact a prerequisite for network teaching, but most network courses are placed on the counter as a " not for sale " --- just for visit and show . Therefore, the teaching management workers and education technology workers shoulder a great responsibility. It can be said, it is an urgent task to promote the application and development of the network teaching . There are two reasons:

\section{A. The demand of the development of education informationization}

Information technology has brought changes in the way of human work, learning, communication, entertainment, psychological and behavioral. For a school, it is not only a new teaching object but also a new teaching media,it is also a new teaching environment . Therefore, education informationization is currently an important issue of education reform. We have difference in understanding, operation modes and other aspects of the education informationization, the network teaching mode is rare which can really combine our country conditions, school situation, the learning situation and the advantages of information technology to improve the quality and efficiency of education ,and universal significance and promote the value. Therefore, building and application network course teaching mode become the positive direction which a number of front-line education technology workers should do in the primary stage of education informationization, thus promoting the healthy development of the education informationization.

\section{B. The demand of course reform and personnel training}

The new course reform is that education initiative adapt to the social development and technological progress at the knowledge economy age. It is the core demands of the course reform that strengthen the subject, social development and student life, promote the diversification the way of students learning, guide students to acquire knowledge independently, create a personality course system and campus culture. Ability of obtain and use information ,it including the ability of acquisition, evaluation , organization, interpretation, and the exchange of information , in particular the use of information technology for self- inquiry, cooperative learning, creative thinking and problem-solving ability.These ability should be essential for students adaptation the social development in the future, it is also the important research direction in the course reform and the integration of information technology. Therefore, it is worthy of study and meaningful research topic that how to use the network environment teaching and how to combine the subject capacity and information capacity .

\section{The Theoretical Basis}

\section{A.Constructivist learning theory}

Constructivist learning theory: individual students acquire knowledge on his own initiative psychological ; learning process is that learners actively construct internal psychological characteristics ; students is the theme of the cognitive processes, the active construction of meaning, students are often in certain situations linked. When new situations is similar with old knowledge structure, it is possible to achieve the knowledge transfer.

Therefore, teacher should be the organizers, promoter and tutorship in the teaching event, teacher also should be advance organizers of the learning content and the creator of the learning context. Teachers should be good at integrating teaching resources, and creating a learning situation , and guiding students to independent inquiry, cooperative learning and help build knowledge systems and ways of thinking, thus forming a good learning attitude, methods, capabilities and habits .

\section{B.Humanistic learning theory}

The humanistic learning theory emphasizes that the self value, development potential, cognizing attitudes, values view have prodigious impact on learning. Students individual have learning potential. Under the right condition , everyone's potential including learning, finding, enriching knowledge and experience can be released . To develop their potential is a learning in the tendency to "self-realization". This learning process is not mechanical links between a simple stimulus and 
reflect, but a meaningful psychological processes . So that, the learning context in the creation of instructional design is particularly important, it is a pivotal tache to stimulate students to release the learning potential.

\section{Measures of Promoting the Network Courses Application}

\section{A.To construct the network teaching platform adapt to schools and professional characteristics}

The school teaching platform applications, is nothing less than the following components : teaching materials ( teachers teaching video ) , electronic teaching plans ,network teaching materials , correlative resources, interactive platform ( online Q \& A, E-mail , forums , etc.), online exam and so on. Constitute is a variety of form, version after another. Select others platform or build their own platform, which platform to choice, should be suitable for the characteristics of the school itself ; such as medical schools should establish live classroom in the platform , abstract thinking specialty should improve the animation multimedia data in order to image understanding , interactive sessions should have considerable proportion in the legal specialty teaching ;

\section{B.Measures of mobilize the students enthusiasm}

\section{1) Optimize educational resources}

Network teaching make educational resources maximize sharing. In the traditional teaching mode, the excellent educational resources can only be fewness people occupy and use because of unenlightened information meaning, result in seriously uneven distribution of resources. The advent of the Internet, lead the traditional information storage state and use mode to a fundamental change, educational resources can be intensive use . Excellent educational resources can be spread through the network allocation so that each educatee in society as a whole can enjoy these educational resources to the most optimal use. For example, in the selection of teachers, you can select the most outstanding teaching video in one speciality.

2) Implementation of the teaching policy

We should really treated learning knowledge through the network courses same as the knowledge gained by the normal classroom, give the same evaluation, such as the credit policy . Of course, there is a lot of work should be done, especially teaching management leaders and institutions should change their ideas, recognize that this is an important part of promoting the development of information technology in education .

3) To give students more free space

Network courses learning give students more space and freedom of time, then , we should create a multi- disposable rights to the students in daily management; to improve student learning interest, so that learning from passive to active, thus it is propitious to culture the creativity and the qualities of the educatee. Educatee is educated with "spoon-fed" passive teaching mode in the traditional teaching , "write notes in the class, memorize notes before exam, tear notes after exam", so that learning becomes a memory knowledge process, lack of innovation , make against the cultivation of all the qualities. Network teaching changed this situation from fundamentally , this mode of learning give educatee a loose opportunities to participate and practice opportunities , this learning environment is conducive to individualized learning and promote personalized active learning, it can fully bring into play the learning initiative and creativity of the educatee.

\section{Measures of mobilizing the enthusiasm of teachers}

\section{1) Teachers play more freedom}

Teacher has a lager play space under the network teaching platform, not only some chores of the classroom part can save ,but also students more fully express the feelings of their hearts and the views feedback such as teaching methods, teaching tache, because of the online communication and 
interaction . Great benefits for improving the level and quality of the teachers, it really realize the teaching and learning promote each other.

2) Time and space freedom administrate

Create more space and time is conducive to not only the development of students, but also the teachers , teachers can follow their own arrangements for operation learning , teaching and research, scientific research ,etc. as long as the school management make reasonable arrangement adapt to the new situation is bound to promote the overall level of school teachers .

3) Innovative encouragement policy

School management should make reasonable adjustments to adapt to the new situations, by use of the scientific concept of development , under the precondition of encourage innovation, promote education reform , training of highly qualified personnel ; establish encouragement policy Which is conducive to the healthy development of the education informationization , encourage teachers participate in the reform innovation. Bringing a new teaching methods need to explore and summarize continuously, you need to pay more for the hard work, there should be a proper evaluation in this regard. In this process, the resulting experiences and lessons are a valuable asset in the future , on the one hand, teachers should pay attention to the accumulation of results, on the other hand, the school should pay attention to this attempt, consider titles and treatment for the teacher.

\section{Conclusion}

The network teaching make the whole educational activities from educators, the educatee even the use of educational resources achieve full democratization, popular and social , which is the traditional teaching mode can't be compared . Data shows that students main body consciousness, innovative spirit and practical ability overall improve, teacher education conception , professional level, theoretical knowledge wholly upgrade by use and carry out network course teaching. school education informationization process can be promoted through the network course teaching, it also improve the visibility of the school. Vigorously carry out and promote the network teaching is a general trend. As technology progress, the further improvement of the network transmission speed, the teaching platform more user-friendly, the maturity degree of the network teaching will be improved; All of these will create an excellent environment to carry out the network teaching deeply.

\section{References}

[1]Youru Xie,Qingchao Ke, Exploration and Application of Network course(M). Beijing Electronic Industry Press, pp.56-60, November 2005.

[2]Shaochun Yang, Songhua Xu, Course of Military University Network Teaching Application System (M). Shanghai: the Second Military University of Medicine Press, 2004.

[3]Kehang He,The new development of educational technology theory and practice in 21st century[J]. Journal of Modern educational technology, pp.5-6, October2009.

[4]Bin Li, Fei Li, Zhaohui Liang, The design research of teacher communion mechanism in network teaching flat[J]. Journal of Chinese Long-distance education, pp.67-69, November2009.

[5]Heping Ke, Wenli Li. Typical teaching mode exploration based on the network course [J].China audio-visual education, 2007, (7) : 71. 